\title{
Erratum to: First evidence for a stereoselective incorporation of nonylphenol diastereomers in soil-derived organo-clay complexes
}

Patrick Riefer $\cdot$ Jan Schwarzbauer • Andreas Schäffer · Timm Klausmeyer • Burkhard Schmidt

Published online: 24 May 2011

(C) Springer-Verlag 2011

Erratum to: Environ Chem Lett

DOI 10.1007/s10311-011-0315-5

The original publication shows the authors' given names as family names and vice versa. The names are correct in this erratum.

The online version of the original article can be found under doi: 10.1007/s10311-011-0315-5.

P. Riefer · J. Schwarzbauer $(\bowtie)$ Institute for Geology and Geochemistry of Petroleum and Coal, RWTH Aachen University, Lochnerstrasse 4-20, 52056 Aachen, Germany

e-mail: schwarzbauer@lek.rwth-aachen.de

A. Schäffer · T. Klausmeyer · B. Schmidt Institute of Environmental Biology and Chemodynamics, RWTH Aachen University, Worringerweg 1, 52074 Aachen, Germany 